\title{
Nicotine dependence among adolescents in the European Union: How many and who are affected?
}

\section{F.R. Coban ${ }^{1,2}$, A.E. Kunst ${ }^{1}$, M.M. Van Stralen ${ }^{2}$, M. Richter ${ }^{3}$, K. Rathmann ${ }^{3,4}$, J. Perelman ${ }^{5}$, J. Alves ${ }^{5}$, B. Federico ${ }^{6}$, A. Rimpelä ${ }^{7,8}$, V. Lorant ${ }^{1,2,9}$, M.A.G. Kuipers ${ }^{1}$}

${ }^{1}$ Department of Public Health, Amsterdam Public Health Research Institute, Academic Medical Center, University of Amsterdam, Amsterdam, The Netherlands

${ }^{2}$ Department of Health Sciences, Faculty of Earth \& Life Sciences, Vrije Universiteit Amsterdam, Amsterdam Public Health Research Institute, Amsterdam, The Netherlands

${ }^{3}$ Institute of Medical Sociology (IMS), Martin Luther University Halle-Wittenberg, Halle, Germany

${ }^{4}$ Faculty for Rehabilitation Science, TU, Dortmund, Germany

${ }^{5}$ Centro de Incestigação em Saúde Pública, Escola Nacional de Saúde Pública, Universidade Nova de Lisboa, Portugal

${ }^{6}$ Department of Human Sciences, Society and Health, University of Cassino and Southern Lazio, Cassino, Italy

${ }^{7}$ School of Health Sciences, Faculty of Social Sciences, University of Tampere, Tampere, Finland

${ }^{8}$ Department of Adolescent Psychiatry, Pitkäniemi Hospital, Nokia, Tampere University Hospital, Tampere, Finland

${ }^{9}$ Institute for Health and Society \& Faculty of Public Health, Université Catholique de Louvain, Brussels, Belgium

Address correspondence to M.A.G. Kuipers, E-mail: m.a.kuipers@amc.uva.nl

\section{ABSTRACT}

Background Nicotine dependence during adolescence increases the risk of continuing smoking into adulthood. The magnitude of nicotine dependence among adolescents in the European Union (EU) has not been established. We aimed to estimate the number of nicotine dependent 15-year-old adolescents in the EU, and identify high-risk groups.

Methods The number of nicotine dependent 15-year-olds in the EU was derived combining: (i) total number of 15-year-olds in the EU (2013 Eurostat), (ii) smoking prevalence among 15-year-olds (2013/2014 HBSC survey) and (iii) proportion of nicotine dependent 15-year-olds in six EU countries (2013 SILNE survey). Logistic regression analyses identified high-risk groups in the SILNE dataset.

Results We estimated 172636 15-year-olds were moderately to highly nicotine dependent (3.2\% of all 15 years old; $35.3 \%$ of daily smokers) In the total population, risk of nicotine dependence was higher in males, adolescents with poor academic achievement, and those with smoking parents or friends. Among daily smokers, only lower academic achievement and younger age of smoking onset were associated with nicotine dependence.

Conclusion According to our conservative estimates, more than 172000 15-year-old EU adolescents were nicotine dependent in 2013 Prevention of smoking initiation, especially among adolescents with poor academic performance, is necessary to prevent a similar number of adolescents getting addicted to nicotine each consecutive year.

Keywords adolescents, dependence, Europe, nicotine, smoking

\section{Introduction}

Smoking prevalence among European adolescents is higher than in other parts of the world, such as Australia and North America. $^{1,2}$ In 2013, around 10\% of European adolescents aged 15-17 years were daily or current smokers, according to self-reported data. ${ }^{3,4}$ At least one-fourth of the adolescent smoking population continues smoking at later age, ${ }^{5,6}$ which may be driven by high levels of nicotine dependence. ${ }^{7,8}$ In turn, persistent smoking increases the risk of developing
F.R. Coban, Master Student

A.E. Kunst, Professor of Social Epidemiology

M.M. Van Stralen, Assistant professor of Health Sciences

M. Richter, Professor of Medical Sociology

K. Rathmann, Assistant professor of Rehabilitation and Participation Sociology

J. Perelman, Assistant professor of Health Economics

J. Alves, Port-doctoral Researcher

B. Federico, Associate Professor of Public Health

A. Rimpelä, Professor of Public Health

V. Lorant, Professor of Medical Sociology

M.A.G. Kuipers, Post-doctoral Researcher 
tobacco related illnesses at later age, and at least half of longterm smokers die of smoking-related diseases.

Nicotine is a highly addictive substance, due to its quick absorption into the bloodstream leading to dopamine release in the brain. ${ }^{7}$ While high dopamine levels cause a pleasant feeling, lower levels cause smokers to crave for the next cigarette. $^{7}$ The adolescent brain is biologically prone to addiction, ${ }^{10}$ making the risk of developing dependence higher in adolescents than in adults. ${ }^{11}$ Nicotine dependence is characterized by experiencing withdrawal when nicotine is absent, feeling relieved within $5 \mathrm{~s}$ after puffing a cigarette, having high cravings for cigarettes, and being behaviourally dependent on nicotine., ${ }^{8,12}$ The first symptoms of nicotine dependence often appear days to weeks after smoking the first cigarette; which is often before the onset of daily smoking. ${ }^{6}$

The prevalence of nicotine dependence among adolescents has been measured on a few occasions. In 1999, 66\% of Canadian adolescent daily smokers with a mean age of 13 years were nicotine dependent, according to ICD-10 and the Hooked on Nicotine Checklist. ${ }^{8}$ Using the Fagerström Tolerance Questionnaire (FTQ), a study in Texas found that 63\% of 15-18 years old current smokers were nicotine dependent in 1999. ${ }^{13}$ A study from Germany in 1995 reported nicotine dependence among $19 \%$ of 14-24-year-old regular smokers. ${ }^{14}$ Additionally, a study in 2007 in Finland reported $44 \%$ of the daily smoking $14-18$ years old population being nicotine dependent. ${ }^{15}$ Latter two studies used the Heaviness of Smoking Index (HSI). These estimates may be out-dated, and there are no previous studies that cover the entire European Union (EU). Therefore, more recent and representative prevalence estimates of nicotine dependence in the EU are required in order to provide insight into the scope of the problem and its persistence in the future among EU adolescents.

Identifying risk groups would provide important information for targeted prevention strategies. Nicotine dependence is for $75 \%$ driven by genetic factors, ${ }^{5,16}$ but environmental factors may play a role, mainly by triggering smoking initiation. Examples of determinants include peer pressure or exposure to smoking by friends and parents, female gender, older age, low socioeconomic status (SES), higher cigarette consumption, and an earlier age of smoking initiation. ${ }^{12,16-24}$ However, risk factors of nicotine dependence among smokers were often not distinguished from risk factors of smoking initiation. The current literature therefore has a limited contribution to a better understanding of where nicotine dependence originates, and what risk factors, after smoking initiation, determine the level of dependence.

The primary aim of this study was to estimate the size of the 15-year-old population in the EU that is nicotine dependent. An additional aim was to identify subgroups that show higher nicotine dependence, either because of higher risk of daily smoking or higher risk of nicotine dependence after smoking initiation.

\section{Methods}

\section{Data and study population}

Data for this study was obtained from the 2013 Eurostat database, ${ }^{25,26}$ the 2013/2014 Health Behaviour in Schoolaged Children (HBSC) report, ${ }^{4}$ and the 2013 Smoking Inequalities: Learning from Natural Experiments (SILNE) survey. $^{27}$ In this study, we combined these data sources to extrapolate the nicotine dependence rates found in SILNE (i.e. six EU countries) to the EU as a whole, using the smoking prevalence data from HBSC. Data from the SILNE survey were additionally used for the analyses of risk groups.

\section{Eurostat database}

Eurostat 2013 provides data on population size per country that was obtained from censuses of 27 EU Member States. ${ }^{25,26}$ We extracted the total number of 15-year-old adolescents, stratified by gender, on 1 January 2013 in the EU.

\section{HBSC report}

The HBSC survey is a repeated cross-national survey regarding adolescents' health in their social context. Representative schools were selected randomly by each EU Member State. We consulted the 2013/2014 survey report, which is based on data of almost 220000 adolescents aged 11, 13, and 15 years in 42 countries of which 27 EU Member States. ${ }^{4}$ Data collection in the survey was carried out through questionnaires in school classes. ${ }^{28}$ Representative schools were selected randomly within each country, and countries followed the same standardized procedures. Daily smoking was measured by asking how frequently respondents have smoked cigarettes during the last 30 days. ${ }^{27}$ We extracted the proportion of daily smoking 15 years old (at least one cigarette per day in the last 30 days), stratified by gender, from in 27 EU countries.

\section{SILNE dataset}

The SILNE survey is a cross-national survey conducted in January-November 2013, including 11015 students aged 13-17 years (79.4\% response rate). ${ }^{27} \mathrm{~A}$ total of 50 secondary schools were selected to represent different levels of SES in six EU cities, representative for the country: Latina (Italy), Tampere (Finland), Namur (Belgium), Hannover (Germany), Coimbra (Portugal), and Amersfoort (The Netherlands). ${ }^{27}$ The questionnaire covered questions on health, smoking, and SES. While the sample of 13 -year-olds was too small, the 
group of 15 years old provided sufficient information to be combined with the HBSC data. Therefore, we included only 15-year-olds ( $N=1852 ; 451$ daily smokers) in this study when we aimed to determine the total number of 15-year-old nicotine dependent daily smoking population. Respondents aged 14-16 years ( $N=9578 ; 1127$ daily smokers) were included in the analyses to identify potential risk groups. The age groups 14 and 16 years old were added to increase the power, due to a too small sample size when only 15 -year-olds were included.

\section{Measures in the SILNE survey}

\section{Nicotine dependence}

Nicotine dependence was measured in the SILNE survey with the Stanford Dependence Index (SDI), containing five questions (see Appendix 1). ${ }^{29,30}$ The SDI was validated for use in the European adolescent population. ${ }^{31}$ The nicotine dependence score was computed as the sum of all five items, ranging from 0 to $20 .^{29,30}$ Among daily smokers, a total of 986 adolescents of all ages answered all five SDI questions (96.7\%), of which 277 were 15 years old and 703 14-16 years old. Missing values among daily smokers were excluded from the analyses $(N=25)$. The Cronbach's alpha of the SDI, calculated in the SILNE survey, was 0.74. Moderate to high nicotine dependence was defined as a nicotine dependence score of $\geq 10$, and lower nicotine dependence was defined as a score of $<10 .^{32}$ This cut-off is used in previous research ${ }^{32}$; however, this cut-off value was not validated.

\section{Smoking}

Smoking status, obtained from the SILNE survey, was dichotomized as daily smokers versus non-(daily) smoker. Adolescents reporting no smoking, having smoked only one or two cigarettes in the last 30 days, or having smoked only one or two cigarettes per week were categorized as non-(daily) smokers. Adolescents smoking at least one cigarette per day were defined as daily smokers.

Age of first cigarette was measured by asking how old respondents were when they first tried smoking cigarettes, even if it were just a few puffs. Answer options were categorized into: 13 years or older (reference category), 12 years old, and 11 years or younger.

Daily cigarette consumption among daily smokers measured how many cigarettes they smoked on average per day during the past 30 days. Answers were categorized as 1-10 cigarettes (reference category), 11-20 cigarettes, or 21 or more cigarettes per day.

\section{Risk group factors}

Potential risk factors for daily smoking prevalence and for nicotine dependence, measured in SILNE, included age, gender, academic achievement, parental education, parental smoking status, and smoking status of friends.

Academic achievement was measured according to marks received during the past academic year. Adolescents were asked: 'Which of the following best describes your school marks during the past year?'. Answers were country-specific, according to the national grading system. ${ }^{33}$ Academic achievement was divided into tertiles, separately for each country. High academic achievement level was the reference category.

Parental education level was reported by adolescents. The highest attained educational level of both the mother and father were reported. The educational level of the most highly educated parent was used in the analyses. Per country, education was categorized into 'low', 'medium', and 'high' (reference category). In general, college or university degree corresponded with high level, upper secondary school and/ or a lower level of college corresponded with medium level, and primary school and/or a lower level of secondary school corresponded with low educational level. 'I don't know' was coded as a separate category.

Parents' and friends' smoking were reported by adolescents. Adolescents were asked: 'Does any member of your household smoke cigarettes?', separately for their father and mother, and, if applicable, their stepfather and stepmother, and dichotomized into at least one smoking parent/stepparent versus no smoking parents/stepparents. Friends' smoking was measured by asking: 'Do any of your best and closest friends smoke cigarettes?'. Answers were: 'none of them' (reference category), 'some of them', 'most of them', or 'all of them'.

\section{Statistical analyses}

To estimate the total number of nicotine dependent 15 -yearold EU girls and boys, we first multiplied the total number of 15-year-old adolescents in the EU (Eurostat data) with the proportion of 15-year-old daily smokers in the EU (HBSC data), which provided the total number of 15-yearold daily smokers in the EU. Secondly, we multiplied the latter number with the proportion of 15-year-old nicotine dependent EU adolescents among daily smokers (SILNE data). This provided the total estimated number of 15 -yearold daily smoking EU girls and boys who were moderately to highly nicotine dependent in 2013. In this calculation, we assumed that the proportion nicotine dependent 15-year-old daily smokers in the six SILNE countries approached the proportion in the EU. 
The risk group analyses were performed in the SILNE dataset, using unadjusted and adjusted logistic regression analyses. Three models for risk groups for the following outcome variables were created: (i) daily smoking prevalence in the total population, (ii) nicotine dependence in the total population, and (iii) nicotine dependence among daily smokers. Adjusted models controlled for age, gender, academic achievement, parental education, and parental and friends' smoking behaviour. For nicotine dependence among daily smokers, cigarette consumption and age of smoking onset were additionally included. For all regression models, we performed a sensitivity analysis using the continuous nicotine dependence scale, in linear regression models.

All statistical analyses were performed in SPSS version 23.

\section{Results}

Table 1 presents the total number of the 15-year-old daily smoking population and the total number of nicotine dependent daily smokers in the EU. In total, $17263615-$ year-old daily smokers in the EU were moderately to highly nicotine dependent in 2013. This corresponds to $35.3 \%$ of the total EU 15 -year-old smoking population, and $3.2 \%$ of the total 15-year-old EU population.

The proportion of 15-year-old adolescents in SILNE for each score on the nicotine dependence scale (SDI) is presented in Fig. 1. The mode is a score of 6 and the median is 8. The histogram shows a slightly right-skewed distribution with a mean of 8.34 and standard deviation of 3.94 .

Table 2 describes the associations between risk factors and daily smoking prevalence, and nicotine dependence (i.e. outcome variables) in adjusted models in the SILNE dataset. Daily smoking was more likely among males, older adolescents, adolescents in the low and middle academic achievement levels (compared to high), and adolescents with smoking parents and smoking friends. Daily smokers with a low level of academic achievement were at increased risk of nicotine dependence (compared to high level), but none of the other risk factors were significantly associated with nicotine dependence among daily smokers. Consequentially, low academic achievement was a risk factor of nicotine dependence in the total population, as well as older age, smoking parents, and smoking friends. The sensitivity analyses showed that the same risk factors were associated with higher scores on the continuous nicotine dependence scale.

Table 3 presents unadjusted and adjusted models for nicotine dependence among daily smokers. Additional to Table 2, cigarette consumption and age of smoking onset were included. After controlling for all other variables, both unadjusted and adjusted models show that nicotine dependence among daily smokers was associated with low academic achievement compared to high performance, consuming 11 or more cigarettes per day compared to 1-10 cigarettes, and younger age of smoking onset. Overall, no significant associations were observed for age, gender, parental education, or smoking behaviour of parents and friends, but confidence intervals are wide. The sensitivity analyses showed that the same risk factors were associated with higher scores on the continuous nicotine dependence scale.

\section{Discussion}

\section{Main findings of this study}

We estimated that more than 172000 15-year-old daily smokers in the EU were moderately to highly nicotine dependent in 2013. This is $\sim 35 \%$ of the 15 -year-old daily smoking population and $\sim 3 \%$ of all 15 -year-olds in the EU. Risk groups of daily smoking and nicotine dependence in the total population included males, older adolescents, adolescents with a lower level of academic achievement, and adolescents with smoking parents or friends. Among daily smokers, risk groups were those with lower academic achievement level, higher cigarette consumption, or younger age of smoking onset.

\section{What is already known on this topic}

We estimated that $35 \%$ of 15 -year-old daily smokers in the EU had moderate to high nicotine dependence. This estimate falls in between North-American estimates of 63 and $66 \%,{ }^{8,13} 44 \%$ in Finland, and 19\% in Germany. ${ }^{14,15}$ The latter study used the Heaviness of Smoking Index (HSI) to quantify nicotine dependence, which includes questions regarding the amount smoked and, therefore, considers consumption an indicator for nicotine dependence. ${ }^{15}$ The SDI only measures behavioural changes due to the availability of nicotine. The higher prevalence according to SDI in the current study compared with the HSI in the German study ${ }^{15}$ reflects that behavioural signs of dependence may already occur at a relatively low level of consumption.

Our results agree with other studies in suggesting that early age of smoking onset (before the 14th birthday) is a risk factor for being nicotine dependent at later age. ${ }^{6,24}$ Nicotine dependence develops quickly after smoking the first cigarette and increases in intensity over time. ${ }^{6,24}$ Earlier age of smoking onset has not only been found to lead to more severe nicotine dependence, but also to more difficulties in smoking cessation at later age. ${ }^{18,34}$ 
Table 1 Smoking prevalence rates (from HBSC), nicotine dependence prevalence rates (from SILNE), and number of nicotine dependent 15-year-old adolescents, stratified by gender

\begin{tabular}{|c|c|c|c|}
\hline & Male $(95 \%$ CI) & Female $(95 \%$ Cl) & Total $(95 \%$ CI) \\
\hline Total N 15-year-old adolescents in EU (Eurostat) & 2726604 & 2589186 & 5315790 \\
\hline Total \% smoking 15-year-old adolescents (HBSC) & $8.9(8.5-9.3)$ & $9.5(9.1-9.9)$ & $9.2(8.9-9.5)$ \\
\hline Total N smoking 15-year-old adolescents in EU & 245182 & 247619 & 492801 \\
\hline $\begin{array}{l}\text { \% Nicotine dependent 15-year-old adolescents among daily smokers } \\
\text { (SILNE) }\end{array}$ & $33.3(27.3-40.0)$ & $36.9(31.0-43.2)$ & $35.3(31.0-39.8)$ \\
\hline Total N nicotine dependent 15-year-old adolescents in EU & 80808 & 90764 & 172636 \\
\hline
\end{tabular}

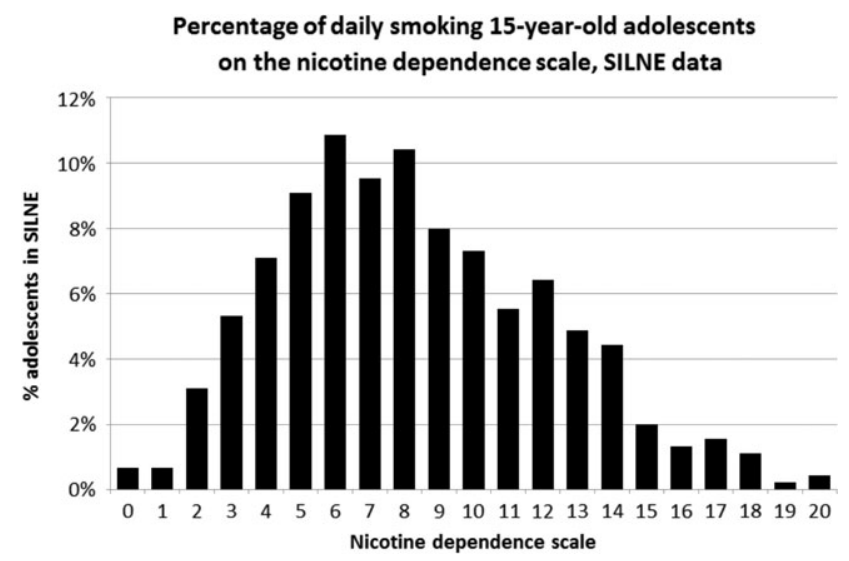

Fig. 1 Proportions of 15-year-old daily smoking adolescents in SILNE ( $N=$ 451) on the nicotine dependence scale, ranging from 0 to 20.

We found that nicotine dependence among daily smokers was barely associated with parental smoking. Given that nicotine dependence is highly heritable, ${ }^{5,11}$ this is a surprising result. However, some previous studies also did not find strong associations between adolescent nicotine dependence and parental smoking or dependence. ${ }^{35,36} \mathrm{~A}$ prospective study found that a positive association between maternal dependence and offspring dependence only emerged in young adulthood. ${ }^{35}$

\section{What this study adds}

The results underline the importance of actively preventing smoking uptake and nicotine dependence among young people. Additional to the estimated 172636 nicotine dependent 15 -year-olds, the total number of dependent adolescents in the EU must be higher, as smokers at age 15 are likely to continue smoking at later age,,$^{7,9,37}$ and many adolescents start smoking at ages over 15 years. ${ }^{38}$ Older adolescents could not be included, as HBSC only contained information on adolescents aged 11, 13, and 15 years. In the SILNE data, we found that 16-year-old smokers show similar proportions of nicotine dependence. This suggests that an increase in nicotine dependence with age would for a larger part be driven by an increase in smoking prevalence, than by an increase in dependence levels among smokers. This is supported by studies among adults in which about half of smokers were nicotine dependent. ${ }^{39,40}$ This also implies that the absolute number of 15 -year-old nicotine dependent adolescents may decrease in the future, due to the decreasing smoking trend in most European countries. ${ }^{41}$

Prevention can take a population approach through the implementation of tobacco control policies, especially increases in the price of tobacco products, mass media campaigns, comprehensive smoke-free policies, smoking curricula in schools, restrictions on marketing opportunities for the tobacco industry, and stronger enforcement of the ban on sales to minors. ${ }^{42-44}$ Additionally, prevention may be targeted at specific groups of adolescents who have increased risk of initiating smoking and developing dependence. ${ }^{45}$ Adolescents who perform poorly in school are an important target group as they have higher risks of both initiating smoking and developing nicotine dependence. Moreover, a greater difference between achievement levels was observed for nicotine dependence than for smoking initiation. This implies that inequalities among adult smokers, among whom low SES smokers were more likely to be nicotine dependent, ${ }^{46}$ already emerge in adolescence. As previously suggested for adults, ${ }^{46}$ an academic gradient in adolescents may be explained by the interaction between psychological stress (e.g. caused by poor academic performance and potential related adverse conditions at home) and the alleged stress relieving properties of smoking. Moreover, adolescents who do poorly in school may tend to accept higher levels of cigarette consumption, as social norms have shown to differ according to academic performance. ${ }^{47}$ Examples of prevention strategies that could target lower SES adolescents include tobacco taxes, education programmes, and tailored mass media campaigns. ${ }^{48,49}$ No proof was found on how improving school attainment would reduce cigarette consumption. 
Table 2 The association between potential risk groups and daily smoking prevalence, nicotine dependence prevalence among daily smokers, and nicotine dependence prevalence in the total population in three adjusted regression analyses among 14-16-year-old adolescents (SILNE survey, $N=9578 ; 1127$ daily smokers)

\begin{tabular}{|c|c|c|c|c|c|c|c|}
\hline & \multicolumn{4}{|l|}{$\mathrm{N}$} & \multicolumn{3}{|c|}{ Adjusted odds ratio (95\% confidence interval) ${ }^{a}$} \\
\hline & $\begin{array}{l}\text { Total } \mathrm{N} \text { in } \\
14-16 \\
\text { years old }\end{array}$ & $\begin{array}{l}\% \text { ND in } \\
14-16 \\
\text { years old }\end{array}$ & $\begin{array}{l}\text { N Daily } \\
\text { smokers }\end{array}$ & $\begin{array}{l}\% \text { ND among } \\
\text { daily smokers }\end{array}$ & $\begin{array}{l}\text { Daily smoking } \\
\text { prevalence in total } \\
\text { population }\end{array}$ & $\begin{array}{l}\text { Nicotine dependence } \\
\text { among daily smokers }\end{array}$ & $\begin{array}{l}\text { Nicotine } \\
\text { dependence in } \\
\text { total population }\end{array}$ \\
\hline \multicolumn{8}{|l|}{ Age } \\
\hline 14 years & 2591 & 2.0 & 169 & 29.1 & Ref. & Ref. & Ref. \\
\hline 15 years & 4242 & 3.9 & 453 & 33.9 & $1.36(1.08 ; 1.72)$ & $1.38(0.90 ; 2.12)$ & $1.74(1.18 ; 2.58)$ \\
\hline 16 years & 2745 & 6.1 & 505 & 30.8 & $1.80(1.42 ; 2.28)$ & $1.23(0.80 ; 1.89)$ & $1.82(1.23 ; 2.70)$ \\
\hline \multicolumn{8}{|l|}{ Gender } \\
\hline Female & 5038 & 4.7 & 566 & 33.1 & Ref. & Ref. & Ref. \\
\hline Male & 4516 & 4.9 & 557 & 31.3 & $1.20(1.02 ; 1.41)$ & $1.08(0.82 ; 1.42)$ & $1.07(0.83 ; 1.37)$ \\
\hline \multicolumn{8}{|l|}{ SES } \\
\hline Academic achievement level & 3964 & 1.7 & 261 & 26.8 & & & \\
\hline High & 3885 & 3.8 & 498 & 28.8 & Ref. & Ref. & Ref. \\
\hline Middle & 1593 & 9.9 & 344 & 40.4 & $1.47(1.21 ; 1.78)$ & $1.17(0.81 ; 1.67)$ & $1.38(0.99 ; 1.93)$ \\
\hline Low & & & & & $1.77(1.42 ; 2.21)$ & $2.24(1.53 ; 3.28)$ & $2.66(1.88 ; 3.77)$ \\
\hline \multicolumn{8}{|l|}{ Parental education level } \\
\hline High & 2314 & 2.4 & 182 & 30.7 & Ref. & Ref. & Ref. \\
\hline Middle & 3497 & 3.7 & 415 & 29.8 & $1.06(0.84 ; 1.34)$ & $0.86(0.57 ; 1.31)$ & $0.86(0.59 ; 1.26)$ \\
\hline Low & 2546 & 5.4 & 380 & 34.4 & $0.97(0.76 ; 1.24)$ & $1.12(0.73 ; 1.70)$ & $1.03(0.70 ; 1.52)$ \\
\hline \multicolumn{8}{|l|}{ Smoking parents } \\
\hline No & 5593 & 1.9 & 353 & 27.2 & Ref. & Ref. & Ref. \\
\hline Yes & 3716 & 7.2 & 743 & 35.3 & $2.13(1.80 ; 2.51)$ & $1.26(0.93 ; 1.69)$ & $1.70(1.30 ; 2.23)$ \\
\hline \multicolumn{8}{|l|}{ Smoking friends } \\
\hline None & 3013 & 0.2 & 21 & 27.8 & Ref. & Ref. & Ref. \\
\hline Some & 4266 & 1.7 & 233 & 25.5 & $2.91(1.89 ; 4.49)$ & $0.78(0.28 ; 2.20)$ & $1.71(0.71 ; 4.08)$ \\
\hline Most & 1757 & 11.4 & 617 & 32.3 & $17.15(11.18 ; 26.31)$ & $0.94(0.34 ; 2.57)$ & $4.12(1.76 ; 9.65)$ \\
\hline All & 286 & 28.7 & 178 & 44.8 & $43.75(26.48 ; 72.29)$ & $1.70(0.60 ; 4.79)$ & $9.03(3.73 ; 21.87)$ \\
\hline
\end{tabular}

${ }^{a}$ All analyses were adjusted for all variables in this table.

Given that nicotine dependence affects more than a third of daily smoking adolescents, it is important that they are offered help to quit smoking. Smoking cessation support may be especially important for adolescents with poorer academic performance, who are at increased risk of nicotine dependence once they initiate smoking. Unfortunately, there is a lack of positive evidence on measures to improve the reach and effectiveness of cessation support services among adolescents. ${ }^{50,51}$ Future studies will need to identify services that can effectively help adolescents who have already become nicotine dependent.

Our study focussed on nicotine dependence related to the use of conventional cigarettes. In addition to these, ecigarettes may also contribute to nicotine dependence in EU adolescents. $^{52}$ High proportions of adolescents in Europe and the USA have tried e-cigarettes, and up to a third of them tried e-cigarettes without using conventional cigarettes. $^{53,54}$ In order to reduce nicotine dependence in adolescents in Europe, controlling their e-cigarette use is essential.

\section{Limitations of this study}

Our estimate of the number of nicotine dependent 15 -yearolds has some degree of uncertainty.

First, to determine nicotine dependence, we used cut-off value of 10 on the $0-20$ SDI scale. This cut-off value was used only in one previous study, and is not validated. ${ }^{31} \mathrm{~A}$ higher threshold would lead to a lower estimate, while a lower threshold would have resulted in a higher estimate of the number of dependent adolescents. Many 15-year-olds scored only just under the cut-off value of 10 on the $0-20$ scale, indicating that some level of dependence is quite prevalent 
Table 3 The association between potential risk factors and nicotine dependence prevalence among 14-16-year-old daily smokers in unadjusted and adjusted logistic regression analyses (SILNE survey, $N=9578 ; 1127$ daily smokers)

\begin{tabular}{|c|c|c|c|c|}
\hline & \multicolumn{2}{|l|}{$\mathrm{N}$} & \multicolumn{2}{|c|}{ Odds ratio (95\% confidence interval) } \\
\hline & N Daily smokers & $\%$ ND among daily smokers & Unadjusted & Adjusted $^{a}$ \\
\hline \multicolumn{5}{|l|}{ Age } \\
\hline 14 years & 169 & 29.1 & Ref. & Ref. \\
\hline 15 years & 453 & 33.9 & $1.58(0.85 ; 1.81)$ & $1.44(0.89 ; 2.33)$ \\
\hline 16 years & 505 & 30.8 & $1.73(0.74 ; 1.58)$ & $1.37(0.85 ; 2.22)$ \\
\hline \multicolumn{5}{|l|}{ Gender } \\
\hline Female & 566 & 33.1 & Ref. & Ref. \\
\hline Male & 557 & 31.3 & $0.99(0.75-1.14)$ & $0.92(0.68 ; 1.25)$ \\
\hline \multicolumn{5}{|l|}{ SES } \\
\hline \multicolumn{5}{|c|}{ Academic achievement level } \\
\hline High & 261 & 26.8 & Ref. & Ref. \\
\hline Middle & 498 & 28.8 & $1.17(0.83 ; 1.49)$ & $1.18(0.79 ; 1.75)$ \\
\hline Low & 344 & 40.4 & $2.27(1.37 ; 2.49)$ & $2.22(1.46 ; 3.37)$ \\
\hline \multicolumn{5}{|c|}{ Parental education level } \\
\hline High & 182 & 30.7 & Ref. & Ref. \\
\hline Middle & 415 & 29.8 & $1.06(0.72 ; 1.39)$ & $0.85(0.54 ; 1.34)$ \\
\hline Low & 380 & 34.4 & $1.39(0.90 ; 1.71)$ & $0.99(0.62 ; 1.59)$ \\
\hline \multicolumn{5}{|l|}{ Smoking parents } \\
\hline No & 353 & 27.2 & Ref. & Ref. \\
\hline Yes & 7433 & 35.3 & $1.31(1.09 ; 1.75)$ & $1.01(0.73 ; 1.40)$ \\
\hline \multicolumn{5}{|l|}{ Smoking friends } \\
\hline None & 21 & 27.8 & Ref. & Ref. \\
\hline Some & 233 & 25.5 & $0.97(0.38 ; 1.86)$ & $1.34(0.43 ; 4.26)$ \\
\hline Most & 617 & 32.3 & $1.19(0.49 ; 2.27)$ & $1.47(0.48 ; 4.52)$ \\
\hline All & 178 & 44.8 & $2.09(0.81 ; 3.95)$ & $1.94(0.61 ; 6.17)$ \\
\hline \multicolumn{5}{|l|}{ Consumption per day } \\
\hline 1-10 cigarettes & 840 & 20.1 & Ref. & Ref. \\
\hline 11-20 cigarettes & 231 & 58.9 & $5.47(3.99 ; 7.50)$ & $4.90(3.41 ; 7.03)$ \\
\hline $21+$ cigarettes & 115 & 62.6 & $6.59(4.32 ; 10.06)$ & $5.57(3.41 ; 9.09)$ \\
\hline \multicolumn{5}{|l|}{ Age of first cigarette } \\
\hline$\geq 13$ years & 635 & 22.8 & Ref. & Ref. \\
\hline 12 years & 229 & 40.0 & $2.44(1.67 ; 2.94)$ & $1.96(1.34 ; 2.88)$ \\
\hline$\leq 11$ years & 260 & 52.2 & $4.22(2.75 ; 4.66)$ & $3.06(2.12 ; 4.42)$ \\
\hline
\end{tabular}

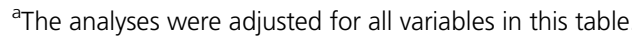

among daily smokers. This study, therefore, may portray conservative estimate of the number of persons that become nicotine dependent during adolescence.

Second, estimates for the six cities in the SILNE data were extrapolated to all EU countries. As the SILNE data did not include eastern European countries, ${ }^{33}$ our estimates may be biased if Eastern EU countries have different nicotine dependence rates among smokers than Western EU countries. Unfortunately, we could not find information on nicotine dependence rates in these countries, and, therefore, are uncertain about the extent of bias this may have caused.
Third, only daily smokers were included in determining the number of nicotine dependent adolescents, while nicotine dependence could also develop among weekly/occasional smokers. ${ }^{11}$ In the SILNE data, among non-daily smokers $(N=199)$, very few were nicotine dependent $(N=5)$. This suggests that the exclusion of non-daily smokers may not have led to a considerable underestimation of nicotine dependence rates in the EU.

Fourth, due to the cross-sectional nature of the data, causal inference should be made with caution. The number of cigarettes consumed showed an association with nicotine 
dependence. This association is known to be bi-directional: heavier smokers show higher nicotine dependence rates, while the dependency leads to smoking higher consumption. ${ }^{17}$

In conclusion, according to the current study's estimates, more than 172000 15-year-old EU adolescents were nicotine dependent in 2013. Prevention of smoking initiation, especially among adolescents with poor academic performance, is necessary to prevent a similar number of adolescents getting addicted to nicotine in each consecutive year. Additionally, it is essential to further study how smoking cessation services can effectively reach and help those adolescents who have already become dependent.

\section{Supplementary data}

Supplementary data are available at the Journal of Public Health online.

\section{Acknowledgements}

The authors would like to acknowledge their colleagues involved in the collection of the SILNE data. This study was presented at the European Conference on Tobacco or Health in Porto, March 2017.

\section{Funding}

This study was supported by the European Commission, Directorate General for Research and Innovation, under the FP7-Health-2011 programme (Grant number 278273), as part of the project 'Tackling socio-economic inequalities in smoking (SILNE)' and the European Commission Horizon 2020 programme, Call PHC6-2014 (Grant number 635056) as part of the SILNE-R project.

\section{References}

1 Dessaix A, Maag A, McKenzie J et al. Factors influencing reductions in smoking among Australian adolescents. Public Health Res Pract 2016;26(1):e2611605.

2 Hublet A, Bendtsen P, de Looze ME et al. Trends in the cooccurrence of tobacco and cannabis use in 15-year-olds from 2002 to 2010 in 28 countries of Europe and North America. Eur J Public Health 2015;25(2):73-5.

3 European Commission. Special Eurobarometer 429 'Attitudes of Europeans Towards Tabacco and Electronic Cigarettes'. 2015 [cited 2016 February, 12th]. http://ec.europa.eu/public_opinion/archives/ebs/ ebs_429_en.pdf.

4 Inchley J, Currie D, Young T et al. Growing Up Unequal: Gender and Socioeconomic Differences in Young People's Health and Well-being [Internet]. World Health Organisation [cited 2016 March, 22nd]. http://www.
euro.who.int/_data/assets/pdf_file/0003/303438/HSBC-No7Growing-up-unequal-full-report.pdf.

5 Kendler KS, Neale MC, Sullivan P et al. A population-based twin study in women of smoking initiation and nicotine dependence. Psychol Med 1999;29(2):299-308.

6 Sockrider M, Rosen JB. Prevention of Smoking Initiation in Children and Adolescents [Internet]. 2016 [cited 2016 April 21st]. http://www. uptodate.com/contents/prevention-of-smoking-initiation-in-childrenand-adolescents.

7 Benowitz NL. Nicotine addiction. N Engl J Med 2010;362(24): 2295-2303.

8 O'Loughlin J, DiFranza J, Tyndale RF et al. Nicotine-dependence symptoms are associated with smoking frequency in adolescents. Am J Prev Med 2003;25(3):219-25.

9 Burns DM. Tobacco-related diseases. Semin Oncol Nurs 2003;19(4): 244-9.

10 Kandel DB, Chen K. Extent of smoking and nicotine dependence in the United States: 1991-1993. Nicotine Tob Res 2000;2(3):263-74.

11 Elders MJ, Perry CL, Eriksen MP et al. The report of the Surgeon General: preventing tobacco use among young people. Am J Public Health 1994;84(4):543-7.

12 Sargent JD, Beach ML, Adachi-Mejia AM et al. Exposure to movie smoking: its relation to smoking initiation among US adolescents. Pediatrics 2005;116(5):1183-91.

13 Prokhorov AV, de Moor CA, Hudmon KS et al. Nicotine dependence, withdrawal symptoms, and adolescents' readiness to quit smoking. Nicotine Tob Res 2001;3(2):151-5.

14 Sonntag H, Wittchen HU, Höfler $\mathrm{M}$ et al. Are social fears and DSM-IV social anxiety disorder associated with smoking and nicotine dependence in adolescents and young adults? Eur Psychiatry 2000;15(1):67-74.

15 Raisamo S, Patja K, Broms U et al. Does self-rated addiction and the heaviness of smoking index predict nicotine replacement therapy product use in adolescent smokers? J Child Adolesc Subst Abuse 2013; 22(4):284-94.

16 Vink JM, Willemsen G, Boomsma DI. Heritability of smoking initiation and nicotine dependence. Behav Genet 2005;35(4):397-406.

17 Flay BR, Hu FB, Siddiqui $\mathrm{O}$ et al. Differential influence of parental smoking and friends' smoking on adolescent initiation and escalation and smoking. J Health Soc Behav 1994;35(3):248-65.

18 Breslau N, Peterson EL. Smoking cessation in young adults: age at initiation of cigarette smoking and other suspected influences. Am J Public Health 1996;86(2):214-20.

19 Breslau N, Fenn N, Peterson EL. Early smoking initiation and nicotine dependence in a cohort of young adults. Drug Alcohol Depen 1993;33(2):129-37.

20 Lessov-Schlaggar CN, Hops H, Brigham J et al. Adolescent smoking trajectories and nicotine dependence. Nicotine Tob Res 2008;10(2): $341-51$.

21 Hiscock R, Bauld L, Amos A et al. Socioeconomic status and smoking: a review. Ann N Y Acad Sci 2012;1248(1):107-23.

22 Kandel DB, Griesler PC, Hu MC. Intergenerational patterns of smoking and nicotine dependence among US adolescents. Am J Public Health 2015;105(11):63-72. 
23 Kandel DB, Hu MC, Griesler PC et al. On the development of nicotine dependence in adolescence. Drug Alcohol Depen 2007;91(1): 26-39.

24 Kendler KS, Myers J, Damaj MI et al. Early smoking onset and risk for subsequent nicotine dependence: a monozygotic co-twin control study. Am J Psychiatry 2013;170:408-13.

25 Population on 1 January by age and sex. 2016 [Internet]. Eurostat. 2013 [cited 2016 March 14th]. http://ec.europa.eu/eurostat/data/ database.

26 Statistics Explained: Population structure and ageing [Internet]. Eurostat. 2016 [cited 2016 March 15th]. http://ec.europa.eu/ eurostat/statistics-explained/index.php/Population_structure_and_ ageing.

27 Lorant V, Soto VE, Moor I et al. Smoking in school-aged adolescents: design and validation of a social network survey in six European cities. BMC Res Notes 2015;8:91.

28 Ianotti RJ. Health Behavior in School-Aged Children (HBSC), 2009-2010, Student Questionnaire. Inter-university Consortium for Political Social Res. 2013, p. 6.

29 Rojas NL, Killen JD, Haydel KF et al. Nicotine dependence among adolescent smokers. Arch Pediatr Adolesc Med 1998;152(2):151-6.

30 O'Loughlin J, Tarasuk J, Difranza J et al. Reliability of selected measures of nicotine dependence among adolescents. Ann Epidemiol 2002;12:353-62.

31 Contreras GA, O’Loughlin J, Rodriguez D et al. Measures of nicotine dependence in adolescents: an update of the evidence 2000-2010. J Pediatr Biochem 2010;1(2):143-64.

32 Killen JD, Robinson TN, Ammerman S et al. Major depression among adolescent smokers undergoing treatment for nicotine dependence. Addict Behav 2004;29(8):1517-26.

33 Kinnunen JM, Lindfors P, Rimpelä A et al. Academic well-being and smoking among 14- to 17-year-old schoolchildren in six European cities. J Adolesc 2016;50:56-64.

34 WHO. Prevalence of Tobacco Smoking. 2016 [cited 2016 August, 5th]. http://www.who.int/gho/tobacco/use/en/.

$35 \mathrm{Hu}$ MC, Davies M, Kandel DB. Epidemiology and correlates of daily smoking and nicotine dependence among young adults in the United States. Am J Public Health 2006;96(2):299-308.

36 Filippidis FT, Agaku IT, Vardavas CI. The association between peer, parental influence and tobacco product features and earlier age of onset of regular smoking among adults in 27 European countries. Eur J Public Health 2015;25(5):814-8.

37 Siahpush M, McNeill A, Borland R et al. Socioeconomic variations in nicotine dependence, self-efficacy, and intention to quit across four countries: findings from the International Tobacco Control (ITC) Four Country Survey. Tob Control 2006;15:71-5.

38 Kuipers MAG, Robert PO, Richter M et al. Individual and contextual determinants of perceived peer smoking prevalence among adolescents in six European cities. Prev Med 2016;88:168-75.
39 Stanton WR. DSM-III-R tobacco dependence and quitting during late adolescence. Addict Behav 1995;20:595-603.

40 HBSC. Publications: Data Visualisations. Tobacco use: Trends in detail [Internet]. (n.d.) [cited 2018 April, 15th]. http://www.hbsc.org/ publications/datavisualisations/tobacco_use.html.

41 Méndez D, Alshanqueety O, Warner KE. The potential impact of smoking control policies on future global smoking trends. Tob Control 2013;22(1):46-51.

42 Sherman EJ, Primack BA. What works to prevent adolescent smoking? A systematic review of the National Cancer Institute's Research-Tested Intervention Programs. J Sch Health 2009;79(9): 391-9.

43 DiFranza JR, Savageau JA, Fletcher KE. Enforcement of underage sales laws as a predictor of daily smoking among adolescents-a national study. BMC Public Health 2009;9(1):107.

44 Pierce JP, White VM, Emery SL. What public health strategies are needed to reduce smoking initiation? Tob Control 2012;21(2):258-64.

45 Wilson LM, Avila Tang E, Chander G et al. Impact of tobacco control interventions on smoking initiation, cessation, and prevalence: a systematic review. J Environ Public Health 2012;2012:961724.

46 Brown T, Platt S, Amos A. Equity impact of intervention and policies to reduce smoking in youth: systematic review. Tob Control 2014;23:98-105.

47 Scherphof CS, Van den Eijnden RJ, Engels RC et al. Long-term efficacy of nicotine replacement therapy for smoking cessation in adolescents: a randomized controlled trial. Drug Alcohol Depen 2014;140: 217-20.

48 Vuckovic N, Polen MR, Hollis JF. The problem is getting us to stop: what teens say about smoking cessation. Prev Med 2003;37(3): 209-18.

49 MacDonald S, Rothwell H, Moore L. Getting it right: designing adolescent-centred smoking cessation services. Addiction 2007; 102(7):1147-50.

50 Stanton A, Grimshaw G. Tobacco cessation interventions for young people. Cochrane Libr 2013;23(8):CD003289.

51 Soneji S, Barrington-TrimisJL, Wills TA et al. Association between initial use of e-cigarettes and subsequent cigarette smoking among adolescents and young adults a systematic review and meta-analysis. JAMA Pediatr 2017;171(8):788-797.

52 Goniewicz ML, Gawron M, Nadolska J et al. Rise in electronic cigarette use among adolescents in Poland. J Adolesc Health 2014;55(5): 713-5.

53 Utah Department of Health. Utah Health Status Update: Electronic Cigarette Use Among Utah Students (Grades 8, 10, and 12) and Adults [Internet]. 2013 [cited 2016 October, 9th]. http://health.utah.gov/ opha/publications/hsu/1312_ECig.pdf.

54 McNeill A, Brose LS, Calder R et al. E-cigarettes: an evidence update. In: A Report Commissioned by Public Health England. London: Public Health England, 2015. 